\title{
PATTERNS OF AGGRESSION IN GULLS: ASYMMETRIES AND TACTICS IN DIFFERENT SOCIAL CATEGORIES ${ }^{1}$
}

\author{
RAYMOND PIEROTTI \\ Department of Systematics and Ecology and Program in Environmental Studies, \\ University of Kansas, Lawrence, KS 66045-2106 \\ Cynthia AnNetT \\ Department of Systematics and Ecology, University of Kansas, Lawrence, KS 66045-2106
}

\begin{abstract}
During contests in Western Gulls, Larus occidentalis, we examined patterns of aggression in relation to sex, age class, and territorial status. Data were collected on agonistic contests during parts of three reproductive seasons on Southeast Farallon Island. This colony has dense nesting territories and appears to be near saturation, making breeding space a limiting and valuable resource. Established, territory-holding male gulls were able to defeat nearly all opponents. The exceptions were a few unestablished adult males early in the reproductive period that appeared to be equal, or superior to, established males in fighting ability and persistence. Established females were able to defend their territories against territory-holding neighbors, immature gulls, and adult female intruders, but often were forced to retreat by unestablished male intruders. Both immature and unestablished adult intruders more readily challenged an established female than an established male.

The value of breeding territories, the primary contested resource, appeared to increase throughout the reproductive period as established birds became increasingly inclined to escalate encounters after eggs were laid, and even more inclined to escalate after chicks appeared. In contrast, unestablished adults became less common and, when present, less inclined to escalate as the season progressed.
\end{abstract}

Key words: Aggression; Larus occidentalis; territoriality; Western Gull.

\section{INTRODUCTION}

Dating back to Darwin (1872), conflicts between conspecifics have been the subject of considerable study (Tinbergen 1951, Lorenz 1966, Maynard Smith and Price 1973, Huntingford and Turner 1987). A key question has been why animals do not fight in every contest situation, "Considering the fact that sexual contests take such an enormous amount of the time of so many species, it is certainly astonishing that real fighting, in the sense of a physical struggle, is so seldom observed" (Tinbergen 1951).

Various explanations have been presented for the scarcity of physical combat, including benefits to the social group (Lorenz 1966). The best explanation appears to be, however, that the costs of physical combat (risk of injury, excessive energetic expenditure), rarely outweigh the benefits to individual contestants (Maynard Smith and Price 1973, Maynard Smith and Parker 1976). Given this situation, animals should develop conventions through which conflicts can be re-

' Received 24 August 1993. Accepted 17 March 1994. solved (Parker 1974, Parker and Rubenstein 1981, Huntingford and Turner 1987).

Conventions for resolving conflicts could be based on differences between individuals in age, size, sex, or physical condition. Conventions could also be based on the value of the contested resource, e.g., food, mate(s), breeding space to the contestants. Given differences, or asymmetries (Maynard Smith and Parker 1976), among individuals and the value of resources to these individuals, it should be possible to predict the outcome of contests between conspecifics.

We analyzed territory-based aggressive behavior in the Western Gull (Larus occidentalis). Data were collected during unmanipulated interactions between seven classes of contestants (see Table 1) during one entire reproductive season and parts of two others. In this species potential asymmetries during the reproductive period which may affect the outcome of contests are based on size, age, sex, and territorial status. Employing simple rules concerning asymmetries among the seven types of contestants should allow us to predict the outcomes of contests between gulls. For example, in asymmetric contests 
where one individual is older, larger, and has more to lose (e.g., established male vs. immature male), that individual will be the winner. However, the winner is not easily predicted for symmetric contests (e.g., established male vs. established male) or for contests where there are conflicting asymmetries (e.g., paired and established female with a territory to lose vs. a larger unestablished male with a mate).

The tactics employed in aggressive encounters may change over the course of the breeding season as a result of changes in the perceived value of the resources to the contestants. For example, the value of the territory should increase for the territory owner because of increased probability that the breeding attempt will be successful as eggs are laid and chicks hatch and are fed and guarded. Territories are also valuable because vacancies become more rare as the season progresses. A pair that is displaced early in the reproductive period could conceivably obtain another breeding territory. As the season progresses, however, it becomes difficult to re-establish and produce a new clutch due to time constraints (Mobley 1993). In contrast, breeding space is most valuable to unestablished birds early in the season when completion of a breeding attempt is still possible. After the peak of chick hatching, available breeding space is of little value for unestablished birds during that season.

\section{STUDY ORGANISM AND METHODS}

Western Gulls are territorial, have several distinguishable age classes, and are sexually dimorphic (Pierotti 1981, Hand 1986). The population on Southeast Farallon Island $\left(37^{\circ} 24^{\prime} \mathrm{N}, 123^{\circ} 00^{\prime} \mathrm{W}\right)$ is the largest breeding colony of this species. During this study, nesting space was a limiting resource and there was severe competition for breeding space $(10,000-13,000$ breeding pairs within an area of 44 ha [Pierotti 1981]). Mean territory size was only $10.2 \mathrm{~m}^{2}(n=33$, range $=$ 4.3-20.2 $\mathrm{m}^{2}$ ), and there were many unestablished adult gulls and immature birds (Pierotti 1981). Since these unestablished birds were continually seeking either nesting or roosting space, it was possible to observe frequent interactions between established and unestablished birds, who could be considered as "owners" and "intruders" (compare, Parker and Rubenstein 1981).

At least four age classes can be recognized in the Western Gull (Dwight 1925). The degree of sexual dimorphism is known in this population, with the mean $( \pm$ SD) weight of females $(879 \pm$ $78 \mathrm{~g}$ ) being only $77 \%$ that of males $(1,136 \pm 47$ $\mathrm{g}$ [Pierotti 1981]). Gull chicks in this population generally reach adult weight before fledging and show a bimodal distribution of weights (Coulter 1977; Pierotti and Annett, unpubl. data); therefore, size differences between the sexes appear consistent across all age groups.

Observations were conducted from a blind, generally from 06:00-21:00 hr each day. Data were collected during the entire breeding season (April-June) of 1974, with supplemental observations conducted during the breeding seasons of 1973 and 1975. Both individuals of 24 pairs of Western Gulls were identifiable from either color-bands (14 birds) or distinctive markings (torn webs on feet, scratches on bills, soiled plumage, etc.). Within each pair, sex was easily identifiable by differences in size and behavior, e.g., the role taken in courtship feeding and copulation. We recorded all observed aggressive interactions that involved members of these 24 pairs during 45 days of observation in 1974 and five days in 1975. Contestants were categorized according to age, sex, and reproductive status (Table 1). We recorded identity of the contestants, initial behavior of each contestant, and subsequent behaviors. Initial behavior was defined as the first act performed by an individual during an interaction, whereas subsequent behavior was defined as the act that followed the response of the opponent. A subset of these interactions was timed using a stopwatch to allow us to compare the duration of interactions between different classes of contestants.

Aggressive behavior was scaled for intensity by placing specific behavioral acts into one of three categories. Acts considered to be of high intensity were fights (involving considerable physical contact), striking or grabbing other individuals, and prolonged aerial pursuits. Each of these activities involved considerable risk of injury and expenditure of energy. Acts of moderate intensity included grass-pulling, short pursuits on the ground with upraised wings, and leaping at or jabbing at an opponent across a territorial boundary. These acts involved considerable exertion, but a low risk of injury. Low intensity interactions were simply ritualized displays, involving little exertion and no risk of injury, such as choking, aggressive upright postures, and long calls (see Tinbergen 1960 and Hand 1986 for description of the displays). 
TABLE 1. Categories of contestants involved in aggressive interactions among Western Gulls and criteria for inclusion in specific categories.

\begin{tabular}{lll}
\hline \hline \multicolumn{1}{c}{ Category } & \multicolumn{1}{c}{ Criteria } & Abbreviation \\
\hline Established Male & Holder of a breeding territory & EM \\
Established Female & Mate of an EM & EF \\
Unestablished Adult & $\begin{array}{l}\text { Bird in adult plumage appeared to be seeking either nesting } \\
\text { space or a mate, a few sexed by size }\end{array}$ & UM or UF \\
& $\begin{array}{l}\text { Bird in plumage other than adult, most sexed by size } \\
\text { Immature }\end{array}$ & EM which attempted to steal food or injure chicks \\
Pirate & IM or IF \\
\hline
\end{tabular}

The reproductive period was divided into prelaying, incubation, and chick (post-hatching to fledging stage [Pierotti 1981]). Aggressive interactions during these periods were analyzed separately in order to examine changes in patterns of aggression which were related to possible changes in resource value over time. All statistical analyses were conducted on the original count data, even if the data are reported as percentages in the tables.

\section{RESULTS}

\section{COSTS OF AGGRESSIVE INTERACTIONS}

We observed several injuries during aggressive interactions that indicate potential costs to the contestants. Nearly all male birds attempting to steal food from neighbors ("pirates" in Table 1) sustained injuries from fights, including primaries torn loose and severe cuts; one bird lost an eye, and another sustained a broken mandible, which presumably led to his demise (he did not return in subsequent years). After losing a fight to a pirate from an adjacent territory, one male deserted his mate and territory (his three chicks subsequently perished). This was an unusual case since only this one male abandoned his territory after losing a fight. Many chicks also sustained injuries during piracies. Eleven of 24 pairs had chicks injured during encounters with pirates in 1973 (see Pierotti 1982 for details).

Although few serious injuries occurred during moderate and low intensity displays, on seven occasions birds involved in vigorous bouts of grass-pulling were observed to pull plant material out of the ground and fall over backwards. Similarly, birds involved in terrestrial pursuits sometimes tripped and fell. Five birds sustained either dislodged, bent, or broken primaries from these falls, and two birds appeared to injure their feet after tripping (one limped for several days, the other had a cut on its middle toe).

\section{AGGRESSION BY ESTABLISHED TERRITORIAL MALES}

The responses of established male gulls (henceforth referred to as EMs) varied over the breeding season (Tables 2, 3, and 5). Overall, the distributions of responses to neighbors (EM and EF combined) and intruders (IM, IF, UM and UF combined; see Table 1 for definitions) were significantly different during each stage of reproduction $\left(P<0.05\right.$ by $\chi^{2}$ contingency test; $\mathrm{df}=$ 2). In general, EMs escalated (employed aggression of high and moderate intensity) more often against intruders and employed low intensity displays predominantly against neighbors.

During the pre-laying period EMs showed no difference in the pattern of initial responses to neighboring males (EMs) and females (EFs; Table 2). However, EMs showed a significantly different pattern of subsequent response in apparently symmetrical contests with other EMs compared with the contests with EFs. Subsequent responses were more likely to be mutual retreat or escalation in the symmetrical contests compared with repeated threat displays of low intensity in asymmetrical contests (Table 2).

In contests with intruders, EMs showed significantly different patterns in response to immature birds (IMs and IFs) than to unestablished adult males (UMs; Table 2; $P<0.05$ by $\chi^{2}$ contingency test). Contests with IMs and IFs (asymmetric with regard to age) were usually terminated quickly with a threat display of moderate or low intensity. In contrast, contests with UMs were predominantly escalated, particularly if the UM responded with a threat, thereby necessitating a subsequent response (Table 2).

The same basic pattern persisted during the incubation period (Table 3). The rate declined from 0.49 to 0.31 interactions $\mathrm{EM}^{-1} \mathrm{hr}^{-1}$. As during pre-laying, EMs interacted primarily in contests with UMs (symmetrical in sex, age, and 
TABLE 2. Behavioral responses of established, territory-holding male Western Gulls in contest situations during the pre-laying period (total number of hours observed $=25$ for each of 24 males).

\begin{tabular}{|c|c|c|c|c|c|c|c|c|c|c|c|}
\hline \multirow[b]{3}{*}{ 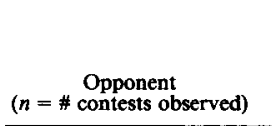 } & \multicolumn{5}{|c|}{ Initial behavior } & \multicolumn{6}{|c|}{ Subsequent behavior } \\
\hline & \multirow[b]{2}{*}{$\begin{array}{c}\% \\
\text { Wary }\end{array}$} & \multirow[b]{2}{*}{$\begin{array}{c}\% \\
\text { Retreat }\end{array}$} & \multicolumn{3}{|c|}{ Aggression intensity } & \multirow[b]{2}{*}{$\begin{array}{l}\text { \% Non- } \\
\text { aggressive }\end{array}$} & \multirow[b]{2}{*}{$\begin{array}{c}\frac{1 / 0}{7} \\
\text { Retreat }\end{array}$} & \multicolumn{3}{|c|}{ Aggression intensity } & \multirow[b]{2}{*}{$P$} \\
\hline & & & $\begin{array}{c}\% \\
\text { High }\end{array}$ & $\begin{array}{c}\% \\
\text { Moderate }\end{array}$ & Low & & & $\begin{array}{c}\% \\
\text { High }\end{array}$ & $\begin{array}{c}\% \\
\text { Moderate }\end{array}$ & $\begin{array}{c}\% \\
\text { Low }\end{array}$ & \\
\hline Other EM $(n=122)$ & 0 & 10.7 & 4.1 & 33.6 & 51.6 & 23.0 & 27.0 & 6.6 & 17.2 & 26.2 & *** \\
\hline $\mathrm{EF}(n=34)$ & 0 & 0 & 2.9 & 26.5 & 70.6 & 38.3 & 17.6 & 2.9 & 8.8 & 32.4 & ns \\
\hline $\mathrm{IM}$ or $\mathrm{IF}(n=27)$ & 0 & 0 & 7.4 & 51.9 & 40.7 & 92.6 & 0 & 3.7 & 3.7 & 0 & ns \\
\hline $\mathrm{UM}(n=96)$ & 0 & 0 & 30.2 & 44.8 & 25.0 & 73.9 & 2.1 & 14.6 & 9.4 & 0 & $* * *$ \\
\hline $\mathrm{UF}(n=12)$ & 0 & 0 & 16.7 & 58.3 & 25.0 & 100.0 & - & - & - & - & ns \\
\hline
\end{tabular}

Chi-square goodness of fit test (conducted on original count data) comparing distributions of initial and subsequent behaviors: ns $=$ not significant or insufficient sample size for statistical analysis; ${ }^{* * *}=P$ less than 0.001 .

size). These contests can be considered either as asymmetric in resource value, or as settled by an "owner-wins" convention (Maynard Smith 1976) with the EM driving off his opponent. A few UMs that were paired (accompanied by a female) and seeking breeding space were very aggressive, however, and became involved in extended intense contests with EMs.

On two occasions UMs were able to establish at least a temporary territory on the observation area. In both cases, the UM landed and challenged resident birds. In the first case, the UM (\#37) first appeared in late April 1973. After several encounters, he defeated an EM in combat. The original territory held by the defeated resident was split between the two males. After his victory, male \#37 was joined by a female, and they remained paired on the territory for the remainder of the study.

Another UM was observed to attempt to establish on a territory in early May of 1975 (Table 4). In this instance, the UM (\#29) tried to take over an area which included portions of the territories (containing nests and eggs) of three pairs. Unestablished male \#29 was involved in re- peated escalated combat against the EMs resident on these territories, particularly against EM \#21, whose territory contained most of the contested area. Unestablished male \#29 defeated EM \#21 on at least three occasions, causing EM \#21 to retreat to the area near his nest from which he could not be dislodged. As with UM \#37, UM \#29 only succeeded in displacing resident males from a portion of their territories. No resident pair was ever forced to abandon its nesting area.

In this second case, the resident EMs continued to attack UM \#29. In encounters following establishment of his temporary territory, when UM \#29 was engaged in combat with one EM, one or more of the other EMs attacked him from different directions (including from behind). Unestablished male \#29 was harassed almost continuously when he was present and was involved in 14 fights during $9.5 \mathrm{hr}$ of observation (Table 4A). Whenever UM \#29 was absent from his territory, established birds of both sexes harassed his mate, frequently forcing her to retreat from the area. This harassment continued for 22 days, after which pair \#29 abandoned the area.

The behavior of the EFs involved in this series

TABLE 3. Behavioral responses of EM Western Gulls in contest situations during the incubation period (total number of hours observed $=51$ for each of 24 males).

\begin{tabular}{|c|c|c|c|c|c|c|c|c|c|c|c|}
\hline \multirow[b]{3}{*}{$\begin{array}{c}\text { Opponent } \\
(n=\# \text { contests observed) }\end{array}$} & \multicolumn{5}{|c|}{ Initial behavior } & \multicolumn{6}{|c|}{ Subsequent behavior } \\
\hline & \multirow[b]{2}{*}{$\begin{array}{c}\% \\
\text { Wary }\end{array}$} & \multirow[b]{2}{*}{$\begin{array}{c}\% \\
\text { Retreat }\end{array}$} & \multicolumn{3}{|c|}{ Aggression intensity } & \multirow[b]{2}{*}{$\begin{array}{c}\text { \% Non- } \\
\text { aggressive }\end{array}$} & \multirow[b]{2}{*}{$\begin{array}{c}\% \\
\text { Retreat }\end{array}$} & \multicolumn{3}{|c|}{ Aggression intensity } & \multirow[b]{2}{*}{$P$} \\
\hline & & & $\begin{array}{c}\% \\
\text { High }\end{array}$ & $\begin{array}{c}\% \\
\text { Moderate }\end{array}$ & $\begin{array}{c}\% \\
\text { Low }\end{array}$ & & & $\begin{array}{c}\% \\
\text { High }\end{array}$ & $\begin{array}{c}\% \\
\text { Moderate }\end{array}$ & $\begin{array}{c}\% \\
\text { Low }\end{array}$ & \\
\hline Other EM $(n=121)$ & 0 & 9.1 & 6.6 & 40.5 & 43.8 & 31.4 & 34.7 & 5.0 & 10.7 & 18.2 & $* * *$ \\
\hline $\mathrm{EF}(n=22)$ & 0 & 0 & 4.5 & 31.8 & 63.6 & 59.1 & 9.1 & 0 & 9.1 & 22.7 & ns \\
\hline IM or IF $(n=41)$ & 0 & 0 & 17.1 & 51.2 & 31.7 & 87.7 & 0 & 4.9 & 4.9 & 2.5 & ns \\
\hline $\mathrm{UM}(n=177)$ & 0 & 0 & 40.1 & 58.1 & 1.7 & 79.8 & 1.1 & 10.7 & 7.9 & 0.5 & ns \\
\hline $\mathrm{UF}(n=14)$ & 0 & 0 & 28.6 & 21.4 & 50.0 & 78.7 & 0 & 0 & 7.1 & 14.2 & ns \\
\hline
\end{tabular}

Chi-square goodness of fit test (conducted on original count data) comparing distributions of initial and subsequent behaviors: ns = not significant Chi-square goodness of fit test (conducted on original count data) comparin
or insufficient sample size for statistical analysis; $* * *=P$ less than 0.001 . 
TABLE 4. Number of aggressive acts observed to occur between one pair of unestablished adult intruders and three established pairs during three days of interaction ( 9.5 hours observation).

\begin{tabular}{cccc}
\hline & \multicolumn{3}{c}{ Intensity level } \\
\cline { 2 - 3 } & High & Moderate & Low \\
\hline
\end{tabular}

\begin{tabular}{lccc}
\hline \multicolumn{4}{c}{ A. Aggressive acts by male gulls } \\
UM \#29 & $18(14)^{*}$ & 27 & 40 \\
Totals for 3 EMs & $30(20)$ & 53 & 89 \\
\multicolumn{4}{c}{ B. Aggressive acts by female gulls } \\
UF \#29 & $0(0)^{*}$ & 1 & 8 \\
Totals for mates of & $1(0)$ & 2 & 12 \\
3 EMs & $1(0)$ &
\end{tabular}

* Number of fights observed as a subset of high intensity aggressive acts.

of interactions is of interest. The mate of UM \#29 only rarely showed any aggression. What little aggression she showed was all ritualized and of low intensity (Table 4B). Unestablished female \#29 was never observed to escalate, even when her mate was being attacked simultaneously by two or three opponents.

The three EFs involved occasionally directed low intensity displays at UM \#29, but spent most of the observation periods incubating, while their mates fought with and threatened UM \#29 and each other. On those occasions when UM \#29 was absent and an EM was incubating, EFs directed low intensity threats at UF \#29 (Table 4B). If UM \#29 returned while this was occurring, the EF involved invariably ran to her nest and relieved her mate who, freed from incubation duties, rushed to challenge UM \#29.

During the chick period the rate of interactions involving EMs increased to 0.35 interactions $\mathrm{EM}^{-1} \mathrm{~h}^{-1}$. Interactions with UMs, however, de- clined markedly from $0.16 / \mathrm{hr}$ during the prelaying and $0.15 / \mathrm{hr}$ during incubation to 0.02 $\mathrm{EM}^{-1} \mathrm{hr}^{-1}$ during the chick period $(P<0.001$ by $\chi^{2}$ contingency test; $\mathrm{df}=2$ ). This resulted because fewer UMs appeared during this period. Symmetrical contests with other EMs and pirates were most common (Table 5). Both initial and subsequent responses to these two categories of opponents were significantly different $(P<0.001$ by $\chi^{2}$ contingency test; $\mathrm{df}=3$ ).

\section{AGGRESSION BY ESTABLISHED TERRITORIAL FEMALES (EFs)}

As with EMs, the overall distributions of responses to neighbors (EMs and other EFs combined) and intruders (IM, IF, UM, and UF combined) were significantly different during each stage of reproduction $(P<0.05$ pre-laying; $P<$ 0.001 incubation; and $P<0.001$ chick period; all by $\chi^{2}$ contingency test; $\mathrm{df}=2$ ). Most aggression directed at neighbors was of low intensity; moreover, EFs directed a lower frequency of escalated aggression at intruders than did EMs $(P$ $<0.001$ by $\chi^{2}$ contingency test; $\mathrm{df}=2$ ). EFs also showed overall lower rates of aggression during all stages of reproduction than did EMs $(P<$ 0.001 by Mann-Whitney $U$-test).

During pre-laying EFs showed no significant differences in distributions of initial or subsequent responses to EMs and EFs (Table 6). They were more likely to be wary or retreat than EMs when faced with all categories of opponents $(P$ $<0.001$ by $\chi^{2}$ contingency test; $\mathrm{df}=2$ ). The only significant difference in response was initial and subsequent responses to UMs (Table $6 ; P<0.001$ by $\chi^{2}$ contingency test). In contrast to EMs, EFs retreated rather than escalated. They also tended to give threat displays rather than escalate as

TABLE 5. Behavioral responses of EM Western Gulls in contest situations during the chick-rearing period (total number of hours observed $=225$ for each of 24 males).

\begin{tabular}{|c|c|c|c|c|c|c|c|c|c|c|c|}
\hline \multirow[b]{3}{*}{$\begin{array}{c}\text { Opponent } \\
(n=\# \text { contests observed })\end{array}$} & \multicolumn{5}{|c|}{ Initial behavior } & \multicolumn{6}{|c|}{ Subsequent behavior } \\
\hline & \multirow[b]{2}{*}{$\begin{array}{c}\% \\
\text { Wary }\end{array}$} & \multirow[b]{2}{*}{$\begin{array}{c}\% \\
\text { Retreat }\end{array}$} & \multicolumn{3}{|c|}{ Aggression intensity } & \multirow[b]{2}{*}{$\begin{array}{l}\text { \% Non- } \\
\text { aggressive }\end{array}$} & \multirow[b]{2}{*}{$\begin{array}{c}\% \\
\text { Retreat }\end{array}$} & \multicolumn{3}{|c|}{ Aggression intensity } & \multirow[b]{2}{*}{$P$} \\
\hline & & & $\begin{array}{c}\% \\
\text { High }\end{array}$ & $\begin{array}{c}q / \% \\
\text { Moderate }\end{array}$ & $\begin{array}{c}\% \\
\text { Low }\end{array}$ & & & $\begin{array}{c}\% \\
\text { High }\end{array}$ & $\begin{array}{c}\% \\
\text { Moderate }\end{array}$ & $\begin{array}{c}\% \\
\text { Low }\end{array}$ & \\
\hline Other EM $(n=490)$ & 0 & 3.9 & 2.9 & 16.1 & 77.1 & 8.8 & 47.3 & 3.3 & 14.9 & 25.7 & *** \\
\hline $\mathrm{EF}(n=97)$ & 0 & 0 & 2.1 & 12.4 & 85.6 & 58.8 & 19.6 & 1.0 & 6.2 & 14.4 & ns \\
\hline IM or IF $(n=156)$ & 0 & 0 & 10.9 & 27.6 & 61.5 & 97.5 & 0 & 1.9 & 0.6 & 0 & ns \\
\hline $\mathrm{UM}(n=123)$ & 0 & 0 & 13.0 & 48.0 & 39.0 & 90.3 & 0 & 2.4 & 5.7 & 0 & ns \\
\hline $\mathrm{UF}(n=33)$ & 0 & 0 & 12.1 & 24.3 & 63.6 & 97.0 & 0 & 0 & 3.0 & 0 & ns \\
\hline Pirate $(n=294)$ & 0 & 0 & 84.0 & 12.2 & 3.7 & 11.1 & 8.2 & 3.1 & 44.9 & 32.7 & *** \\
\hline
\end{tabular}

Chi-square goodness of fit test (conducted on original count data) comparing distributions of initial and subsequent behaviors: $n$ s $=$ not significant or insufficient sample size for statistical analysis; ${ }^{* * *}=P$ less than 0.001 . 
TABLE 6. Behavioral responses of EF Western Gulls in contest situations during the pre-laying period (total number of hours observed $=25$ for each of 24 females).

\begin{tabular}{|c|c|c|c|c|c|c|c|c|c|c|c|}
\hline \multirow[b]{3}{*}{$\begin{array}{c}\text { Opponent } \\
(n=\text { contests observed })\end{array}$} & \multicolumn{5}{|c|}{ Initial behavior } & \multicolumn{6}{|c|}{ Subsequent behavior } \\
\hline & \multirow[b]{2}{*}{$\begin{array}{c}\% \\
\text { Wary }\end{array}$} & \multirow[b]{2}{*}{$\begin{array}{c}\% \\
\text { Retreat }\end{array}$} & \multicolumn{3}{|c|}{ Aggression intensity } & \multirow[b]{2}{*}{$\begin{array}{c}\text { \% Non- } \\
\text { aggressive }\end{array}$} & \multirow[b]{2}{*}{$\begin{array}{c}\% \\
\text { Retreat }\end{array}$} & \multicolumn{3}{|c|}{ Aggression intensity } & \multirow[b]{2}{*}{$P$} \\
\hline & & & $\begin{array}{c}\% \\
\text { High }\end{array}$ & $\begin{array}{l}\text { \% Mod- } \\
\text { erate }\end{array}$ & $\begin{array}{l}\% \\
\text { Low }\end{array}$ & & & $\begin{array}{c}\% \\
\text { High }\end{array}$ & $\begin{array}{l}\text { \% Mod- } \\
\text { erate }\end{array}$ & $\begin{array}{l}\% \\
\text { Low }\end{array}$ & \\
\hline $\operatorname{EM}(n=78)$ & 28.2 & 11.5 & 3.8 & 11.5 & 44.9 & 60.3 & 19.2 & 1.3 & 3.8 & 15.4 & ns \\
\hline Other EF $(n=43)$ & 30.2 & 9.3 & 7.0 & 11.6 & 41.9 & 32.6 & 16.2 & 2.3 & 14.0 & 34.9 & ns \\
\hline IM or IF $(n=18)$ & 11.1 & 0 & 5.6 & 44.4 & 38.9 & 83.2 & 5.6 & 5.6 & 5.6 & 0 & ns \\
\hline $\mathrm{UM}(n=41)$ & 17.5 & 10.0 & 2.5 & 15.0 & 57.5 & 22.5 & 45.0 & 5.0 & 17.5 & 10.0 & $* * *$ \\
\hline $\mathrm{UF}(n=12)$ & 0 & 0 & 25.0 & 42.0 & 33.0 & 83.3 & 0 & 16.7 & 0 & 0 & ns \\
\hline
\end{tabular}

Chi-square goodness of fit test (conducted on original count data) comparing distributions of initial and subsequent behaviors: ns $=$ not significant or insufficient sample size for statistical analysis; ${ }^{* * * *}=P$ less than 0.001 .

their initial response to UMs. This is not surprising, for UMs were larger than EFs so there was a high risk of injury to the EFs in escalated contests.

During the incubation period EFs showed a low frequency of aggression $\left(0.05 \mathrm{hr}^{-1}\right.$ compared with $0.17 \mathrm{hr}^{-1}$ during pre-laying) and, while on the territory, spent most of their time incubating (Pierotti 1981). Their overall response patterns were virtually identical to those during pre-laying except for a tendency to escalate against immature intruders (Table 7), probably as a response to potential egg predators.

During the chick period, aggression by EFs reached its peak $\left(0.22 \mathrm{hr}^{-1}\right)$. The pattern of EF responses was affected by category of opponent. For example, initial EF responses given to EMs and EFs were similar but subsequent responses were different (Table $8 ; P<0.001$ by $\chi^{2}$ contingency test). Retreat was the most common subsequent response in symmetrical contests with other EFs. Distributions of initial and subsequent responses to all classes of intruders were significantly different (Table $8 ; P<0.001$ by $\chi^{2}$ contingency test), with EFs escalating initially against pirates (who were male and larger) and directing threat displays against other intruders. In subsequent behavior, EFs increased the frequency of escalation against all opponents except pirates.

During all three stages of reproduction, EFs were involved in significantly fewer fights than were EMs (Table 9). Both fights in which EFs were involved during incubation were against EMs attempting to force copulation. Five of the seven fights in which EFs were involved during the chick stage were against pirates, and the other two were against EMs that had attacked the EFs offspring.

\section{AGGRESSION BY INTRUDERS}

As has been mentioned above, established birds responded differently to all three classes of intruders. These differences appeared related to the behavior of the intruder and its social category. The vast majority of immature males (IMs) and females (IFs) were either wary or retreated immediately (Table 10A). Only a few of these birds employed displays of low intensity as their initial

TABLE 7. Behavioral responses of EF Western Gulls in contest situations during the incubation period (total number of hours observed $=51$ for each of 24 females).

\begin{tabular}{|c|c|c|c|c|c|c|c|c|c|c|c|}
\hline \multirow[b]{3}{*}{$\begin{array}{c}\text { Opponent } \\
(n=\text { contests observed })\end{array}$} & \multicolumn{5}{|c|}{ Initial behavior } & \multicolumn{6}{|c|}{ Subsequent behavior } \\
\hline & \multirow[b]{2}{*}{$\begin{array}{c}\% \\
\text { Wary }\end{array}$} & \multirow[b]{2}{*}{$\begin{array}{c}\% \\
\text { Retreat }\end{array}$} & \multicolumn{3}{|c|}{ Aggression intensity } & \multirow[b]{2}{*}{$\begin{array}{l}\text { \% Non- } \\
\text { aggressive }\end{array}$} & \multirow[b]{2}{*}{$\begin{array}{c}\% \\
\text { Retreat }\end{array}$} & \multicolumn{3}{|c|}{ Aggression intensity } & \multirow[b]{2}{*}{$P$} \\
\hline & & & $\begin{array}{c}\% \\
\text { High }\end{array}$ & $\begin{array}{c}\% \\
\text { Moderate }\end{array}$ & $\begin{array}{c}\% \\
\text { Low }\end{array}$ & & & $\begin{array}{c}\% \\
\text { High }\end{array}$ & $\begin{array}{c}\% \\
\text { Moderate }\end{array}$ & $\begin{array}{c}\% \\
\text { Low }\end{array}$ & \\
\hline $\mathrm{EM}(n=21)$ & 23.8 & 14.3 & $9.5^{\mathrm{a}}$ & 14.3 & 48.1 & 42.9 & $9.5^{\mathrm{a}}$ & 9.5 & 4.8 & 19.0 & ns \\
\hline Other $\operatorname{EF}(n=18)$ & 16.7 & 5.6 & 0 & 16.7 & 61.1 & 27.8 & 22.2 & 0 & 16.7 & 33.3 & ns \\
\hline IM or IF $(n=9)$ & 0 & 0 & 33.3 & 22.2 & 44.5 & 88.9 & 0 & 11.1 & 0 & 0 & ns \\
\hline $\mathrm{UM}(n=26)$ & 23.1 & 15.4 & 3.8 & 11.5 & 46.2 & 19.3 & 53.8 & 7.7 & 15.4 & 3.8 & ** \\
\hline $\mathrm{UF}(n=8)$ & 0 & 0 & 25.0 & 62.5 & 12.5 & 50.0 & 0 & 25.0 & 25.0 & 0 & ns \\
\hline
\end{tabular}

Chi-square test between distribution of initial and subsequent responses: ${ }^{* *}=P$ less than 0.01 .

all high intensity aggression directed at EM attempting forced copulations. 
TABLE 8. Behavioral responses of EF Western Gulls in contest situations during the chick period (total number of hours observed $=225$ for each of 24 males).

\begin{tabular}{|c|c|c|c|c|c|c|c|c|c|c|c|}
\hline \multirow[b]{3}{*}{$\begin{array}{c}\text { Opponent } \\
(n=\# \text { contests observed })\end{array}$} & \multicolumn{5}{|c|}{ Initial behavior } & \multicolumn{6}{|c|}{ Subsequent behavior } \\
\hline & \multirow[b]{2}{*}{$\begin{array}{c}\% \\
\text { Wary }\end{array}$} & \multirow[b]{2}{*}{$\begin{array}{c}\% \\
\text { Retreat }\end{array}$} & \multicolumn{3}{|c|}{ Aggression intensity } & \multirow[b]{2}{*}{$\begin{array}{l}\text { \% Non- } \\
\text { aggressive }\end{array}$} & \multirow[b]{2}{*}{$\begin{array}{c}\% \\
\text { Retreat }\end{array}$} & \multicolumn{3}{|c|}{ Aggression intensity } & \multirow[b]{2}{*}{$P$} \\
\hline & & & $\begin{array}{c}\% \\
\text { High }\end{array}$ & $\begin{array}{l}\text { \% Mod- } \\
\text { erate }\end{array}$ & $\begin{array}{c}\% \\
\text { Low }\end{array}$ & & & $\begin{array}{c}\% \\
\text { High }\end{array}$ & $\begin{array}{l}\text { \% Mod- } \\
\text { erate }\end{array}$ & $\begin{array}{l}\% \\
\text { Low }\end{array}$ & \\
\hline $\mathrm{EM}(n=247)$ & 25.2 & 18.7 & 7.3 & 7.3 & 41.6 & 43.9 & 24.8 & 1.1 & 8.8 & 21.4 & ** \\
\hline Other EF $(n=247)$ & 33.2 & 13.0 & 6.1 & 7.3 & 40.5 & 23.0 & 18.6 & 4.5 & 5.7 & 48.2 & ns \\
\hline IM or IF $(n=129)$ & 11.6 & 0 & 2.3 & 8.5 & 77.5 & 69.0 & 1.6 & 3.1 & 10.1 & 16.2 & $* * *$ \\
\hline $\mathrm{UM}(n=53)$ & 20.8 & 3.8 & 3.8 & 16.7 & 54.7 & 18.9 & 26.4 & 11.3 & 20.8 & 22.6 & $* * *$ \\
\hline $\mathrm{UF}(n=31)$ & 0 & 0 & 9.6 & 19.4 & 71.0 & 9.6 & 6.5 & 22.6 & 35.5 & 25.8 & *** \\
\hline Pirate $(n=197)$ & 0 & 8.1 & 28.9 & 38.6 & 24.3 & 34.5 & 19.3 & 7.6 & 13.7 & 24.9 & *** \\
\hline
\end{tabular}

Chi-square goodness of fit test (conducted on original count data) comparing distributions of initial and subsequent behaviors: $\mathrm{ns}=\mathrm{not}$ significant or insufficient sample size for statistical analysis; $*=P$ less than $0.01 ; * * *=P$ less than 0.001 .

behavior, and none initially employed acts of moderate or high intensity.

Immatures challenged EFs significantly more often than EMs (Table 10A; $P<0.05$ by $\chi^{2}$ contingency test). Nearly $90 \%$ of IMs and IFs fled from EMs either immediately before or after the EM directed a display at them. A smaller percentage $(82 \%)$ fled from EFs $\left(P<0.001\right.$ by $\chi^{2}$ goodness of fit test).

Unestablished adults that challenged residents were all males (UMs; $n=207$ ). Every unestablished adult that could be identified as a female (UF) retreated when challenged by an established bird $(n=44)$. As initial behavior, UMs directed acts of low or moderate intensity at $53 \%$ of EMs and $54 \%$ of EFs (Table 10B). Intruding UMs were more inclined to escalate and less inclined to retreat when involved in contests with a smaller EF $\left(P<0.001\right.$ by $\chi^{2}$ goodness of fit test $)$. Most fled when challenged during symmetrical contests with EMs, and only a few escalated. In contrast, over $25 \%$ escalated against an EF which challenged them, which suggests that the asymmetry in size (or sex) was an important factor.

Although unestablished birds were present on the Southeast Farallon colony throughout the reproductive period, nearly all of the escalated ag-

TABLE 9. Number of fights observed in which male and female gulls participated. At least 1 male was involved in each fight. No female-female fights were observed during the entire study.

\begin{tabular}{lccc}
\hline & \multicolumn{3}{c}{ Stage of reproduction } \\
\cline { 2 - 4 } & Pre-laying & Incubation & Chick \\
\hline Males & 19 & 7 & 20 \\
Females & 0 & 2 & 7 \\
\hline
\end{tabular}

gression directed at established birds was confined to the pre-laying period and early stages of incubation. Over $85 \%$ ( 78 of 91) of initial acts, and over $93 \%$ (61 of 65 ) of subsequent acts of high and moderate intensity, were observed prior to 1 June. In contrast, only $56 \%$ (138 of 245$)$ of acts of low intensity by unestablished adults were observed prior to this time.

All 491 attempted piracies were essentially escalated contests. In each case, an EM or EF returned to its territory and attempted to feed its chicks. As the parent bird regurgitated food, a male bird (sometimes, but not always, from an adjacent territory) would dash in and attempt to steal the regurgitated food. This always elicited instantaneous escalation from one or both of the resident birds. The pirate in turn escalated to defend itself until it could retreat. Nearly half of the males followed in this study acted as pirates at least some of the time (Pierotti 1980, 1981); pirates frequently stole food from and fought with each other.

\section{DURATION OF INTERACTIONS}

The shortest interactions that we observed occurred between established males and immature intruders, with most lasting $10 \mathrm{sec}$ or less (Table 11). Interactions between established females and immature birds averaged longer $(P<0.01$ by Mann-Whitney $U$-test), but the distributions were similar in that both were skewed to the right, with the female distribution having a longer tail ( $F=2.76, P<0.005$, run on variances).

Interactions between established birds (males, females, and pirates) were also short. These interactions lasted longer than interactions with immatures primarily because of their escalated nature. There were no significant differences in 
TABLE 10. Behavioral responses of both immature and unestablished adult intruders towards resident birds.

\begin{tabular}{|c|c|c|c|c|c|c|c|c|c|c|}
\hline \multirow[b]{3}{*}{ 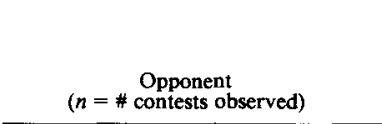 } & \multicolumn{5}{|c|}{ Initial behavior } & \multicolumn{5}{|c|}{ Subsequent behavior } \\
\hline & \multirow[b]{2}{*}{$\begin{array}{c}\% \\
\text { Wary }\end{array}$} & \multirow[b]{2}{*}{$\begin{array}{c}\% \\
\text { Retreat }\end{array}$} & \multicolumn{3}{|c|}{ Aggression intensity } & \multirow[b]{2}{*}{$\begin{array}{l}\text { \% Non- } \\
\text { aggressive }\end{array}$} & \multirow[b]{2}{*}{$\begin{array}{c}\% \\
\text { Retreat }\end{array}$} & \multicolumn{3}{|c|}{ Aggression intensity } \\
\hline & & & $\begin{array}{c}\% \\
\text { High }\end{array}$ & $\begin{array}{c}\text { \% Mod- } \\
\text { erate }\end{array}$ & $\begin{array}{c}\% \\
\text { Low }\end{array}$ & & & $\begin{array}{c}\% \% \\
\text { High }\end{array}$ & $\begin{array}{c}\text { \% Mod- } \\
\text { erate }\end{array}$ & $\begin{array}{c}\% \\
\text { Lou }\end{array}$ \\
\hline \multicolumn{11}{|c|}{ A. Immature non-breeding birds } \\
\hline Established Male $(n=224)^{\mathrm{a}, \mathrm{b}}$ & 81.3 & 12.1 & 0 & 0 & 6.7 & 12.1 & 86.6 & $\mathbf{0}$ & 0.4 & 0.9 \\
\hline Established Female $(n=156)$ & 78.2 & 7.7 & 0 & 0 & 14.1 & 7.6 & 82.1 & 0 & 5.8 & 4.5 \\
\hline \multicolumn{11}{|c|}{ B. Unestablished adult birds } \\
\hline Established Male $(n=439)^{\mathrm{b}, \mathrm{c}}$ & 41.0 & 5.2 & 0.5 & 10.5 & 42.8 & 5.2 & 86.6 & 4.8 & 2.7 & 0.7 \\
\hline Established Female $(n=170)$ & 37.1 & 4.1 & 4.7 & 20.6 & 33.5 & 4.1 & 70.0 & 8.2 & 10.6 & 7.1 \\
\hline
\end{tabular}

" Differences between distribution of initial responses to established males and females significant at 0.05 level by Chi-square test ( 2 df).

- Difference between distribution of subsequent responses to established males and females significant at 0.001 level by Chi-square test ( 1 df for immatures, 3 df for unestablished adults).

immatures, 3 df for unestablished adults).

duration of these interactions between EMs and EFs. Coefficients of variation for these interactions were the lowest of any class (Table 11, F $=1.31, \mathrm{~ns}$ ).

The longest interactions between established birds and intruders were with UMs (Table 11). Distributions for both EMs and EFs were strongly skewed to the right, because of extended persistence times for a few intruders. These interactions had the highest coefficients of variation of any class, and there were no significant differences between EMs and EFs $(F=1.3$, ns). Nearly half of the unestablished intruders fled in less than $30 \mathrm{sec}$, but several persisted for several minutes. In a few cases unestablished intruders persisted for hours or even days (UM \#29), or became established (UM \#37) (these individuals were not included in the statistical analysis).

Durations of interactions between neighbors tended to be less skewed in their distributions. The longest interactions on average were between EMs (Table 11). These generally consisted of extended bouts of displays. The next longest set of interactions was between EMs and EFs (Table 11). Most bouts initiated by EMs with EFs were shorter than bouts between EFs (Table 11).

\section{DISCUSSION}

In general, individual gulls altered their tactics both over the course of the reproductive period, and in relation to which role (e.g., territory holder or intruder) they occupied in a specific interaction. For example, UM \#37 initially fought as an intruder, but later became established and interacted with his neighbors in a ritualized fashion typical of patterns of interaction between es- tablished birds. No established birds were ever permanently displaced from their territories, even when other birds became successfully established on part of their territory.

The way in which gulls switched between roles, changed tactics over time, and fought only in certain specific contexts lends support to the idea that gulls approximate an optimal assessor strategy in which individuals can modify tactics in response to different categories of opponents (sensu Parker and Rubenstein 1981). No previous study on an unmanipulated vertebrate has demonstrated such plasticity in tactics.

Most interactions we observed conformed to simple rules based on asymmetries in fighting ability and resource values. Four classes of interactions did not: (1) neighbor-neighbor interactions, (2) forced attempts at copulations, (3) piracies, and (4) some contests between UMs and

TABLE 11. Duration of interactions (in seconds) between established male and female Western Gulls and different categories of opponents. Interactions lasting over 2 min were not included in this analysis $(<10 \%$ of all interactions).

\begin{tabular}{lcc}
\hline \hline \multirow{2}{*}{ Opponent } & Established Male & Established Female \\
\cline { 2 - 3 } Established Male & $x \pm \mathrm{C.V}$. & $x \pm \mathrm{C.V}$. \\
\hline Established Female & $24.2 \pm 3 \pm .5 \pm 34.8$ & $28.5 \pm 33.68$ \\
& $(n=43)$ & $(n=22)$ \\
Immature intruder & $10.5 \pm 53.5$ & $14.5 \pm 6.5 \pm 32.07$ \\
& $(n=40)$ & $(n=39)$ \\
Unestablished adult & $37.8 \pm 76.9$ & $36.3 \pm 64.5$ \\
intruder & $(n=37)$ & $(n=33)$ \\
Pirate & $29.7 \pm 31.4$ & $29.6 \pm 27.5$ \\
& $(n=49)$ & $(n=35)$ \\
\hline
\end{tabular}


either EMs or EFs. By examining these interactions in more detail we can gain insight into other factors that might be important.

Encounters between established male neighbors are generally symmetrical with regard to size, sex, and value of contested resources, a situation which should lead to the most escalated and lengthy fights (Parker and Rubenstein 1981), yet EMs rarely engaged in physical combat. Maynard Smith and Parker (1976) pointed out that territorial individuals may not fight because neighbors know each other and have a history of interactions which will affect the outcome of the interactions under study. Indeed, as in Great Tits, Parus major (Krebs 1982), most neighborneighbor interactions were of low intensity and short duration. Gulls established conventions over weeks of interactions, and had little to gain by fighting their neighbors. As a consequence, established territorial birds of both sexes show tactics that conform closely to those of so-called "doves," who settle contests through ritualized displays (Maynard Smith and Price 1973).

These results suggest that very simple rules derived from game theory may apply to territorial individuals. Other studies have demonstrated that individuals fighting with unfamiliar intruders over a territory show frequent escalation (e.g., Krebs 1982, Austad 1983). In addition, neighbors may base their assessments of their opponents on information gained from previous encounters, and may not fight over resources that have already been contested.

In this light, it is interesting to examine other classes of contests which do not conform to predictions. While EF-EM interactions were normally of low intensity, if the EM attempted to either force copulation or steal food from the EF, escalated contests often ensued. All escalated fights in which females participated resulted from one of these two behaviors by EMs (Table 9).

The behavior of pirates is difficult to interpret in terms of game theoretical models. An EM acting as a pirate breaks the conventions established over many weeks of encounters with its neighbors, since all piracies are functionally escalated contests. Encounters with pirates were short in duration and pirates invariably retreated, whether or not they were successful in stealing food. The value of the contested resource was low compared to the potential cost in terms of injury. Why pirates should take such risks for little obvious gain is not easily understood. It is possible that this behavior could be interpreted in terms of discrete ESS models, as either a "hawk" or "bully" tactic (Maynard Smith and Price 1973) or such behavior might be considered as either spiteful (sensu Wilson 1975, Pierotti 1980) or pathological.

Pirates were EMs that had lost most or all of their offspring and frequently attacked the chicks of other pairs (Pierotti 1980, 1981, 1982). Their behavior might therefore be viewed as an attempt to reduce the fitness of conspecifics, even at some risk to themselves. Given this, it is not surprising that both EMs and EFs readily escalated against pirates, and that most of the high intensity aggression during the chick period was directed at pirates. Residents defending the lives of their offspring are defending a considerable investment, which they could not recoup during the current breeding season (Mobley 1993). This would create a major asymmetry favoring residents. This is especially apparent in the behavior of EFs, who were less inclined to escalate to acts of high intensity against pirates than were their mates. EFs probably had a greater risk of injury against an opponent who is larger. In this case, however, there is such a large potential cost asymmetry that the EF is willing to drive off the intruder in spite of the risk.

Finally, a few contests involving UMs and either EMs or EFs were not resolved according to simple rules. Although many UMs fled from residents, over $50 \%$ threatened, and some $(5 \%$ against EF) even escalated against established birds (Table 10). The aggressive UMs were probably comparable to EMs in size and age, and were larger than EFs. By challenging established individuals, they were acting in the role of "assessor" (Parker 1974, Parker and Rubenstein 1981) or "prober-retaliator" (Maynard Smith and Price 1973). Since over 50\% of UMs opened encounters by directing an aggressive act of low or moderate intensity at residents, this can be interpreted as either a test of the resident's willingness to defend, or as a possible mistake in role identification (sensu Hammerstein and Parker 1982).

That these challenges are actually assessments, rather than mistakes, is supported by the observation that UMs are more likely to escalate against an EF and more likely to flee or retreat from an EM. This result is expected since males are larger than females, and the intruder should be able to distinguish between male and female opponents. Such cases illustrate how contests 
evolve when there are contradictory asymmetries (Parker and Rubenstein 1981). The EF probably has more to gain from the resource yet her risk of injury against a larger opponent forces her to retreat. Note, however, that EFs never lose their territories in these situations since any persistent intruders must eventually face her mate, who is their equal or superior in nearly all circumstances.

The roles in agonistic behavior taken by Western Gulls appear to conform to various predictions of game theoretical based models, including several derived from the simple models proposed by Maynard Smith and Price (1973). The observed flexibility in tactics, however, suggests strongly that, although early genetically based models provide useful insights (see also Stearns 1992), these tactics are not fixed and genetically driven, but are instead ontogenetically and socially plastic, role driven and adjustable to specific circumstances.

\section{ACKNOWLEDGMENTS}

We thank G. Divoky, T. Rowell, D. Winkler, and R. Ydenberg for comments on earlier drafts of this paper, and T. Good, J. Hunt, E. C. Murphy, C. Welch, and an anonymous reviewer for comments on the current manuscript. We also thank the U.S. Fish and Wildlife Service for permission to work on Southeast Farallon Island Federal Wildlife Refuge.

\section{LITERATURE CITED}

Ainley, D. G., AND R. J. Boekelheide. 1990. Seabirds of the Farallon Islands. Stanford Univ. Press, Stanford, CA.

Austad, S. N. 1983. A game theoretical interpretation of male combat in the bowl and doily spider (Fontinella pyramitela). Anim. Behav. 31:59-73.

Coulter, M. C. 1977. Patterns of growth and the third chick disadvantage in the Western Gull. Ph.D.diss., Univ. of Pennsylvania, Philadelphia.

DARWIN, C. 1872. On the expression of the emotions in man and animals. John Murray, London.
Dwight, J. 1925. The Gulls (Laridae) of the world: their plumages, moults, variations, relationships and distribution. Amer. Mus. Nat. Hist. Bull. 52.

HAND, J. 1986. Territory defense and associated vocalizations of Western Gulls. J. Field Ornithology $57: 1-15$.

Hammerstein, P., AND G. A. Parker. 1982. The asymmetric war of attrition. J. Theor. Biol. 96: $647-682$.

Huntingford, F. A., AND A. K. Turner. 1987. Animal conflict. Chapman and Hall, London.

KREBS, J. R. 1982. Territorial defence in the Great Tit (Parus major): do residents always win? Behav. Ecol. Sociobiol. 11:185-194.

LORENZ, K. 1966. On aggression. Methuen, London.

MAYNARD SMITH, J. 1976. Evolution and the theory of games. Am. Sci. 64:41-45.

Maynard Smith, J., AND G. A. Parker. 1976. The logic of asymmetric contests. Anim. Behav. 24: 159-175.

Maynard Smith, J., and G. R. Price. 1973. The logic of animal conflicts. Nature 246:15-18.

Mobley, J. 1993. Multiple vs. single breeding attempts per season and the effects of time in life history evolution. Ph.D.diss., Univ. of Arkansas, Fayetteville.

Parker, G. A. 1974. Assessment strategy and the evolution of animal conflicts. J. Theor. Biol. 47: 223-243.

PARker, G. A., AND D. I. Rubenstenn. 1981. Role assessment, reserve strategy, and acquisition of information in asymmetric animal conflicts. Anim. Behav, 29:221-240.

PIEROTTI, R. 1980. Spite and altruism in gulls. Amer. Nat. 115:290-300.

Pierotti, R. 1981. Male-female roles in the Western Gull under different environmental conditions. Auk 98:532-549.

Pierottl, R. 1982. Spite, altruism, and semantics. Amer. Nat. 119:116-120.

Stearns, S. C. 1992. The evolution of life histories. Oxford Univ. Press, Oxford, England.

TINBERGEN, N. 1951. The study of instinct. Oxford Univ. Press, Oxford, England.

TINBERGEN, N. 1960. The Herring Gull's world. Basic Books, New York.

WILson, E. O. 1975. Sociobiology: the new synthesis. Harvard Univ. Press, Cambridge, MA. 